\title{
A TRAINING PROGRAM FOR NURSING STAFF REGARDING BLOOD PARASITES ACQUIRED BY NEEDLE STICK INJURY IN A MILITARY HOSPITAL
}

\section{By}

\author{
AHMED MEGAHED AHMED SALEH ${ }^{1}$, SAMIA MOHAMMAD ADAM ${ }^{2}$, \\ ABEER MOHAMMAD ABDALLAH IBRAHIM ${ }^{1}$, \\ AND TOSSON A. MORSY ${ }^{3}$ \\ Military Medical Academy ${ }^{1}$, Departments of Nursing Administration ${ }^{2}$, \\ and Parasitology ${ }^{3}$, Faculties of Nursing ${ }^{2}$ and Medicine ${ }^{3}$, \\ Ain Shams University, Cairo $11566^{2,3}$, Egypt
}

\begin{abstract}
Nurses are likely to be exposed to microorganisms during their daily practice due to their close and frequent direct contact with patients. This could be one of the main causes of transmitting infection to the patients. Therefore, nurses should demonstrate the ability to effectively utilize principles of infection control, nurses should have professional and ethical responsibilities to make sure that their knowledge and skills regarding infection control are up-to-date and they practice safely and competently at all times. Aim: At assessing the effect of a training program for Military nursing staff knowledge, performance and attitude related to blood parasites acquired by needle stick injury.

Setting: The study was carried out at two military hospitals. Design An interventional study (pre-post study) was used. Subject: The studied subjects were 90 nursing staff who accepted to participate in the study (10) of them pilot study were excluded from the study sample, (30) from The Military Fever Hospital and (50) from The Military General Hospital. Tools: The study tools used were composed of five tools as follows: (1) Educational needs assessment tool. (2) Knowledge questionnaire sheet (pre / post-test) (3) Observation check list (4) Attitude tool and (5) Participants 'evaluation Questionnaire sheet. Results: Educational the intervention showed statistically significant improvements in nursing staff knowledge, performance and attitude. Recommendation: Continues training programs about blood parasites acquired by needle stick injury must be developed and provided on regular basis, this will enable nursing staff to improve their knowledge, performance and attitude about blood parasites acquired by needle stick injury.
\end{abstract}

Key words: Military Nursing Staff, blood parasites, needle stick injury

\section{Introduction}

The blood and infectious body fluids (BBF) exposures are common safety problems for health care workers (HCWs) and analyzed reported BBF exposures. Over a 3year period at a teaching hospital the needlestick injuries were the commonest reported BBF exposure, accounting for $80 \%$ of reported cases. Nurses had the highest percentage $(60.6 \%)$ of BBF exposures and other job categories including physicians, technicians, cleaning staff, and interns accounted for about $10 \%$ each. Injuries occurred most commonly during the daytime $(57.0 \%)$. Three-quarters $(74.9 \%)$ of the injured HCWs had appropriate immediate care (Hsieh et al, 2006).
Sharps injuries pose a serious threat to health professionals, patients, and downstream workers. Medical Sharp means object or instrument which is used for carrying out activities to healthcare and which is able to cause injury by means of cutting or piercing the skin; Injury includes infection (Adams et al, 2013). Safer sharp means a medical sharp that was designed and constructed to incorporate a feature or mechanism which prevents or minimizes the risk of accidental injury from cutting or piercing skin (Statutory Instrument, 2013).

The renewed interest in parasitic diseases in the United States markedly increased numbers of persons in clinical and research laboratories have the potential for exposure 
to parasites and therefore are at risk for acquiring parasitic infections concentrated on protozoan diseases that frequently have been reported to be laboratory acquired: malaria, leishmaniasis and toxoplasmosis (Herwaldt and Juranek, 1993). These diseases can be severe, even fatal, and may be difficult to diagnose. Even persons who are expert on parasitic diseases often do not know what clinical manifestations to be expected when natural modes of transmission are bypassed, how to monitor for infection after accidental exposures, and whether to begin the presumptive antimicrobial therapy before infection is documented (Galazzi et al, 2014).

Nursing remains at the front line of patient care, satisfaction and safety by identifying and addressing patient problems in a timely fashion, improve the quality and consistency of medical care in acute hospital settings have been highlighted in a number of UK and international reports (Mackintosh et al, 2014) to maintain the ability of the profession to respond effectively to a dynamic health care system, the Institute Of Medicine (IOMs) Future of Nursing indicated the need for nurses to practice to the fullest extent of their education, achieve higher levels of education, and become full partners in the redesign of healthcare (IOM, 2010).

The changing in the nature of nursing practice with the delivery of more acute care support, including medications is incumbent upon practitioners to minimize these risks and other occupational hazards with the careful assessment of risk and the adoption of recommended practices to maintain their safety and wellbeing. Employers have a duty of care to their employees, but nurses also have responsibilities as employees (Abdenour et al, 2013).

Infection control standards become an integral part of the accreditation program for all medical setting in Egypt, where the National Guidelines for Infection control (NGIC) are produced and established by the infection control team at the Ministry of Health \& Population (MOHAP) since the year 2003 (Ibrahim and Hamdy, 2013). Infection control standard precautions include certain measures such as hand hygiene, sharps safety, staff health, use of personal protective equipment (PPE), equipment safety, single use policy, waste management and environmental cleaning. Many infection control measures, such as appropriate hand hygiene and the correct application of basic precautions during invasive procedures are simple and of low-cost, but require staff accountability and behavioral change, in addition to improving staff education, reporting and surveillance systems. Therefore, adequate nursing staff is necessary because a higher patient- to nurse ratio increases the risk of nosocomial infection (Hugonnet et al, 2007; Bouallegue et al, 2013). Nurses are likely to be exposed to microorganisms during their daily practice due to their close and frequent direct contact with patients. This could be one of the main causes of transmitting infection to the patients (Maltezou et al, 2008).

Therefore, nurses should demonstrate the ability to effectively utilize principles of infection control, nurses should have professional and ethical responsibilities to make sure that their knowledge and skills regarding infection control are up-to-date and they practice safely and competently at all times (French, 2007; Royal College of Nursing, 2012). Thus, education about infection prevention and control was targeted as one of the main objectives of infection control program especially where nurses represent the largest group of health care workers within the healthcare system (WHO, 2008; Rasslan, 2011).

The current study dealt with four zoonotic infectious diseases encountered in Egypt, which are risky to health care Staff by blood transfusion or even by needle-stick. These are: malaria, babesiosis, toxoplasmosis and infantile visceral leishmaniasis.

Significance of the study: All the time nursing staff is the front line of health care team who face patients, so, early detection and rapid reporting which considered from Nursing Golden 
Responsibilities and utmost important for taking the decision for isolation, treatment and disease spread prevention. In general, there is a lack of knowledge among the nursing staff and infection control nurses about blood parasites acquired by needled stick injury, although there is Threequarters $(74.9 \%)$ of the injured health care workers (HCWs) had appropriate immediate care (Hsieh et al, 2006).

Therefore, it was thought that a tailored educational program would help in improving nursing staff knowledge and attitude related to blood parasites acquired by needle-stick injury to improve the quality of nursing care, to acquaint the Egyptian Military Nursing Staff particularly those who share with the Peace Keeping Forces Mission to endemic areas with such fatal diseases. The four blood infectious parasitosis were selected due to their Egyptian epidemiology importance. These zoonotic blood parasites are malaria In there is less awareness and knowledge about these diseases. These diseases were encountered in Egypt; malaria (Saleh et al, 2016) and its Anopheles vectors (El-Bahnasawy et al, 2011), babesiosis (Saleh et al, 2015a) and its tick vector (Morsy, 2012), toxoplasmosis (Saleh et $a l, 2014)$ and leishmaniasis (El-Bahnasawy et al, 2013) and its Phlebotomis vector (Saleh et al, 2015b).

This study assessed the effect of a training program for Nursing Staff knowledge and attitude regarding blood parasites acquired by needle stick injury in Military Hospitals by 1- Assessing knowledge of Military Nursing Staff related blood parasites acquired by needle stick injury. 2- Assessing performance regarding applying safety measures in the handling and disposal of sharps instruments. 3- Assessing the attitude of Military Nursing Staff related to safety measures in the handling and disposal of sharps instruments. They were 80 nursing staff working in Military hospitals 30 from fever hospital and 50 from general hospital Designing and implementing an educational training program, for military nurses on selected infectious blood parasites acquired by needle stick injury based on their need assessment.

\section{Results}

The results are shown in figures (1 to 12).

\section{Discussion}

Continuing education plays a significant role in equipping nurses to deal with the ma- jor changes currently making an impact on healthcare. They need competencies that ensure quality of care to help them perform their job (Fey and Miltner, 2000). Moreover, they stated that in this time of rapid scientific and technological change continuing education is assuming an increasingly important role in health care professions. Controlling and minimizing workplace hazards for healthcare personal (HCP) in hospitals present a unique challenge because the health and wellbeing of hospital patients must also be considered. The safety professionals must work to control occupational exposures in a way that does not interfere with safe patient care (Theresa et al, 2013).

Risk factors for staff nurses injure are related to a false movement during a procedure, re-assembling devices and handing devices to a colleague. The highest proportion of needle stick injuries is related to recapping of used needles especially during the cleaning process (IEA, 2011). In Egypt, approximately $40 \%$ of nurses had experience at least one injury in the past year. Most who had an injury did not report it (WHO, 2012).

Although there is evidence that knowledge among healthcare personnel about prevention measures in occupational exposure to blood and body fluids is adequate, transferring this knowledge into practice remains inadequate. Data on workers attitudes and risk perception about biological risk are poor. Several comments declare detecting "the perception" of biological risk, but actually detected only the knowledge about risk (Sreedharan et al, 2010).

Nurses who are employed in health care workplaces face a serious danger that may threaten their life; it is their exposure to blood and body fluids (BBF). Indeed, accidental exposure may lead to infections by blood borne pathogens, BBPs (Yao et al, 2010).

Lack of nurse knowledge about blood parasite infectious diseases, their way of transmission, symptoms and signs, ways of protection can negatively affect the nature 
and spread of these diseases among military troops (Twum and Meredith, 2003).

Regular and continuous education plays a significant role in equipping nurses to deal with the major changes currently making an impact on healthcare. Educational programs can over light any health topic and bring it into focus in order to help nurses to face any needed action (Fey and Miltner, 2000).

In the present study, at the Fever Hospital the age ranged from (19-39), more than half of them were in the age category 21-30years (67\%); while at the General Hospital the age ranged from (17-39), about (48\%) of them were in the age category less than $20 y$. This difference in age was significant, which helped in assessing its relation with the level of knowledge, practice and attitude. The years of experience ranged from (3-15) at the Fever Hospital, but in both hospitals $56.7 \%$ had less than $5 y$. The great majority (96\%) were females. This dominance was explained by Nikki and Campos (2010) that nursing is a feminine job with excellence; in addition to novices of men in that career only $5 \%$ of nurses were men. Moreover the first organization for men nursing that encourage men to join the nursing career was introduced in USA only in 1971 (Dubey et $a l, 2011)$. The majority $(68 \%)$ were single. Jeff (2008) mentioned that nursing in military sector is time consuming with excess load of work making them having no time for marriage and make males afraid of being busy with their stressful career away from family duties. Nurses (80\%) carried Nursing School diploma; with significant difference in educational levels. As to Rank the majority of them were sergeants at the two hospitals about $(90 \%)$; there was variation in the level of education which shown its impact on the exam answer in the tests of program.

In order to design the educational program, the first step in planning any professional development was to assess the learning needs target group or individual to determine the structure of the program in terms of objectives, content, and activities, learn- ing needs could be individual, organizational, or societal and must be clearly defined during the planning process (Lynor and Desilet, 2007). Thus, learning needs assessment was crucial in the educational process (Grant, 2002). Besides, learning needs analysis was a central component of continuing professional development but lack of psychometrically developed learning needs assessment tools and self-assessment questionnaires emerged as a key method (While et al, 2007). This was in contradictory with training need assessment done by Itrat et al. (2009) prior to the educational program as they conducted an interventional study and reported that the most studied topic and the program was tailored and specific and they relayed that on national interest of that particular topic.

The present study showed that $(60 \%)$ of nurses at Fever Hospital and (70\%) at General Hospital had attended course(s) of infection control. This was agreed with the Iranian study group had previous courses on isolation, standard precaution and the majority stated they needed to attend such courses. They relayed on proper infection control committee acts and commitment and raised awareness of HCWs towards importance of training (Askarian et al, 2007). However, in the present study none attended any training program on infectious blood parasites that was not dealt with nosocomial infectious blood parasites. Thus, the findings displayed that the all of their needs was related to definition of infectious blood parasites, and CCOHS (2005) reported that needle stick injuries are common hazard. Also, Singru and Banerjee (2008) found that needle-stick injuries and cuts were the common occupational accidents exposing HCWs to blood and body fluids $(61.0 .6 \%)$ to NSIs. Some hospitals reported that at least one third of nursing and laboratory staff suffered such injuries annually. Besides, Soknes, (2005) reported in 2001 reduced in NSIs exposure from $(52 \%)$ to only $(28 \%)$ due to good application of infection control. 
In the present study, nurses (76.73) asked to know about infection control measures at Fever Hospital and (58\%) at general hospital. No doubt, nurses lacked knowledge related to infection control measure did not attend such education subject. Vij et al. (2001) reported that highly educated nurses had higher knowledge regarding principles of infection control.

In the present study, all participants were eager to know blood parasites transmitted by blood or needle stick injury specifically those encountered in Egypt. Kovats et al. (2001) reported that the main cause of attending program by trainee was to improve their knowledge about diseases they may face. Also, Molyneux (2003) found that the majority of HCWs needed to attend cession on malaria, which was a problem in their country. But, majority of nurses needed to know their role in application of infection control $(90 \%)$ at Fever Hospital and $(68 \%)$ at General Hospital, which agreed with Frankel (2008) who reported the nurse leaders must demonstrate resilience in responding to change and supporting others to embrace this in a positive way. Effective leaders should be capable of reframing the thinking of those whom they are leading, enable them to see the changes were not only imperative but also achievable. Dyson et al. (2009) found that education for nursing staff it was not always systematically planned and developed and often relied on the interest area and assessment of the nurse educators.

Knowledge is valuable mainly to think in more profound ways, including recall or recognition of facts, procedural patterns, and concepts that serve in the development of intellectual abilities and skills an intellectual skill gained during a course of study which can be transferred to other situations (Sausa, 2006). Knowledge is acquired through formal and informal study in conjunction with experience in a specific domain of nursing practice (Considine et al, 2007). The present study results agreed with Carmela et al. (2012) who found nurses training and knowledge were able to reduce the risk of accidents by exposure to biological agents. Also, Lipscomb et al. (2009) reported that among health care workers, nurses appeared to be more exposed to biological risk, retrospective studies indicated that between $45 \%$ and $46.7 \%$ were exposed to work injuries, with prevalence of needle stick injuries (53$63.6 \%$ ) mostly on hands $76.3 \%$. Accidental exposures to blood and body fluids were also frequent among nurses of operating theater. In the United States showed low prevalence of training and high rate of underreporting of needle sticks and other exposure accidents were $48.9 \%$ (Gershon et al, 2007).

In the present study, all nurses had knowledge about occupational exposure and the important factor that enhances infection transmission. This agreed with Alwutaib et al. (2012) who found that acceptable knowledge level regarding modes of diseases transmission among nurses. However, Ahmed et al. (2008) reported that the minority of their nurses and laboratory technicians had unsatisfactory knowledge about mode of transmitting blood-borne diseases and their signs and symptoms.

In the present study, there were highly significant differences $(\mathrm{p}<0.001)$, related to the most items of malaria at pre, post and follow up phase. There were high significant differences $(p<0.001)$ related to babesiosis at pre, post and follow up phase.

In the present study, there were highly significant differences $(\mathrm{p}<0.001)$ related to infantile visceral leishmaniasis at pre, post and follow up phase fever. This agreed with assessment of knowledge done by Ausburn, (2004) after application of educational program about leishmania regarding types, prevention and treatment. The question-byquestion analysis showed that all participants (with exception of zoonosis control agents) had poor knowledge of leishmaniasis symptoms, $40 \%$ of both groups confused VL with tegumentary leishmaniasis.

In the present study, the nurses had satisfactory knowledge level as regard toxoplas- 
mosis with high statistically significant differences $(\mathrm{P}<0.001)$, as compared with pre, post and follow up phase. This agreed with Kaye (2011) who found that it was important for nursing staff be aware of toxoplasmosis, recognize when it should be considered as a differential diagnosis, and understand how it is diagnosed and treated.

The present study showed the median scores of nursing staff knowledge about four diseases throughout the program three phases; Pre, Post and follow up phase, with high significant differences $(p<0.001)$, indicating improvement of knowledge levels. Fey and Miltner (2000) found that when the knowledge score of almost all participants improved after the program, compared to that before program implementation proved that they were highly interested in the program contents, added by media and teaching method. Tweed and Tweed (2008) reported that complication of the educational program resulted in improved levels of knowledge. The present study showed that all nurses at the fever hospital were good in total knowledge at post- test. Most of the participants at the General Hospital (98\%) categorized good in total knowledge at post- test. Also, there was highly statistical difference $(\mathrm{P}$ $<0.001$ ) indicating significant improvement of knowledge score in post-test as compared to pre-test. This agreed with Cummingham (1998) who found that difference between pre and post-test of knowledge for all participants in educational program, which indicated that learning occurred among participants on the same line. Besides, the effectiveness of intervention, impact, program importance and group discussion increased knowledge level of nurses and improved the quality of health care services. Dyson et al. (2009) reported that ongoing education for nursing workforce was necessary and that education costs were high to the organization and attendance and must therefore be cost-effective, relevant and appropriate.

In this study, there was insignificant difference between nurses 'staff knowledge levels as regard knowledge and age groups, sex, education level, years of experience, working department and martial statuses at fever hospital. Tweed and Tweed (2008) found no differences in knowledge levels between staff members with different levels of experience, qualifications, and seniority, and no association between demographic data and test scores. Also, there was no relation between nursing rank and knowledge level, which might be due to the fact that rank was just an administrative issue depended upon number of years the nurses in the job and advancement to the next rank didn't need new knowledge or skills. Forder (2007) reported that level of knowledge depended upon nurses' capability to learn and self enhancement of career. In this study, nurses in age group more than $30 \mathrm{y}$ obtained the highest total mean \% knowledge score $(39.50 \pm 9.978)$ than other age groups.in relation to marital status and sex, widowed/ divorced nurses obtained the highest total mean \% knowledge score $(39.00 \pm 11.533)$. Also, nurses with work experience of 11-20y obtained highest total mean \% knowledge score $(38.07 \pm 11.605)$. The nurses have bachelor degree, and officer obtained the highest total mean \% knowledge score (39.11 \pm 10.620$)$. Thus, there were significant relations between nurses' characteristics (age, experiences, marital status, qualification, sex \& rank) and their knowledge level. Thibault et al. (2003) found that younger ages were associated with higher satisfactory knowledge due to new graduation and refresh in last years. Powell et al. (2002) noticed that age affected knowledge level. Parhizi (2013) found that high significant relation between nursing staff level of knowledge and ages. Gilboy (2005) reported that only regular training programs significantly affected the level of knowledge. Andersson et al. (2006) linked between years of experience and level of knowledge and that each year increased knowledge by 5\%. Fornaciari et al. (2009) reported that the more experience means more activities, 
more patients' contact and more knowledge Nurses having bachelor degree of nursing obtained highest knowledge score. Generally, the education curriculum of bachelor degree included more valuable and update medical topics. Samuel et al. (2009) found that level of education was positively correlated to knowledge level. Sharma et al. (2010) said that nurses with diploma degree had lower knowledge level than those with bachelor degree and he explained that by different educational contents. However, Pinheiro (2010) highlight that the level of education alone didn't be a clear indicator for the level of knowledge and should be accompanied with training programs as well as the daily usual practice. Pages et al. (2010) clarified that the level of education was not related to knowledge level in developing countries where education depended upon retain not understanding and provided huge amount of information to the student not in an interesting manner.

In the present study, $93.3 \%$ of nurses had highest performance at pre- program and increased to (100\%) at post program and follow up at Fever Hospital and at the General Hospital about (36\%) had perform proper hand washing at pre-program and increased to $(88 \%)$ at post program and follow up. Pittet (2001) reported that factors influencing adherence by healthcare professionals to hand washing included skin irritation, interference with the worker-patient relationship, patient needs perceived as a priority, insufficient time, and high workload and understaffing, lack of scientific information showing impact of improved hand hygiene on hospital infection rates and ignorance and/or disagreement with relevant guidelines and protocols. Currie et al. (2011) reported that perfect hand washing technique and commitment to hand wash criteria and guidelines as a good indicator of success of infection control committee, good program and supervision. Idang et al. (2014) stated that practice of hand washing was considered to be most effective means of preventing health care associated infections but poorly performed.

In the present study there were significant differences between pre; post and follow up related to all items of hand hygiene. The hand washing basin and good water supply were available (100\%) but paper towel not available as reported by all studied group. Siegel et al. (2007) listed hindrances to noncompliance to hand washing to include, Ineffective and inadequate provision of water, lack of appropriate facilities and materials in health care setting. NHS surveillance (2010) reported that hand wash facility was available and enough but with defect bio-waste management and facilities. Consequently, hospital authority should provide standard guidelines on hand washing in all wards for nurses to refresh their memory with good supervision. The importance of hand hygiene must be done in different situations concerned with patients (before and after attendance; before performing invasive procedures; after contact with blood, body secretions; etc...). During the intervention phase; nurses learned the hand washing importance as protective measure. A nurse was also in need of closing to supervision and observation to be considered hand washing as a part of her behavior before, after and during any procedure.

In the present study, there were significant differences between pre, post and follow up related to all items concerning personal protective equipment (PPE). The gowns and gloves were available $(100 \%)$ but nurses said goggles and face shields neither available nor enough $100 \%$ that indicated provision of goggles and face shields and also poor knowledge and attitude towards importance of goggles and face shields. Kabbash et al. (2007) stated that protocols for prevention, PPE measures and post exposure prophylaxis were mostly not available or not accessible in the studied units of hemodialysis in Egypt. Singru and Banerjee (2008) reported shortage in provision of masks and gown that cause muco-cutaneous 
exposure to blood.

As to gowns at fever hospital the participants $(80 \%)$ at pre-program increased to $(100 \%)$ and at general hospital $(92 \%)$ was $\mathrm{HCP}$ wear gown during procedures at the pre-program and increased to $(96 \%)$ at post program. The rates of gown usage agreed with Curtis (2008) where $76 \%$ of healthcare providers and staff used gowns in patient care. Also, Vaz et al. (2010) reflected positive role of infection control team in orientating newly joined staff about wearing of PPE to reduce risk of exposing skin or mucous membranes to infectious materials.

The present study, showed that needles and syringes were used only for one patient $(100 \%)$ at the two hospitals, but the worst $(70 \%)$ at fever hospital and $(76 \%)$ at general hospital pre- program were disinfection of the rubber septum on a medication vial with alcohol prior to piercing, due to inadequate knowledge about safety injection, absence of guidelines and lack of supervision. Alamgir et al. (2007) mentioned that although regulations and hospital policies discouraged recapping of conventional needles and encouraged point of use disposal containers, examination of injury description reported that recapping occurred when using conventional needle. Also, Abdel Hamed et al . (2010) reported single use of syringe by HCWs in all hospital wards due to ethics and obligation regarding syringe usage and precautions. Abdel-Razik and Abdel-Rahman (2011) found that in relation to wastes and sharp disposal, nurses used sharp container for needles and sharp devices, used red bags for infamous and pathologic waste and black bags for general wastes. They added that most needle-stick injuries occurred during syringe recapping or bending after use. The present study found that the proper practice and compliance to guidelines regarding handling and disposal of sharps, had waste bags are securely fasted when $3 / 4$ full at fever hospital about $(12 \%)$ at pre-program increased to $(84 \%)$ at post program and follow up. At the general hospital (63\%) pre-program in- creased to (100\%) at post program and follow up.

The present study, reported that $(63 \%)$ nurses waste bags were securely fasted when $3 / 4$ full at pre-program increased $(100 \%)$ at post program and follow up at fever hospital and $(72 \%)$ at pre- program increased $(94 \%)$ at post program and follow up at general hospital due to inadequate knowledge, training, and lack of supervision on wastes handling, inadequate resources. Ferreire and Teixeira (2010) reported higher risk perception and adherence to procedures concerning waste disposal and sharps and needles handling and disposal. The present study, displayed significant differences between pre, post and follow up related to all items related to waste management.

The present study, demonstrated actual performance of the military nursing exposure control plan immediate action, at fever hospital $(13.3 \%)$ had immediate action (injured person) at pre- program increased to $(93.3 \%)$ at post program and follow up and at general hospital $(6 \%)$ reported the incident immediately to the department at pre- program increased $(92.3 \%)$ at post program and follow up. This agreed with data provided by the Central Register of Occupational Diseases in Poland indicated that among 314 new cases of occupational diseases in healthcare workers, HBV and HCV represented $42.6 \%$ of all cases (Wilczynska et al, 2005).

The present study displayed high significant differences $(\mathrm{p}<0.001)$, between pre, post and follow up related to all items related to exposure control plan immediate action after injury.

This study showed the median scores of military nursing staff performance about (hand hygiene, personal protective equipment, injection safety, handling and disposal of sharps, waste management and exposure control plan) throughout the three phases of the program pre, post and follow up phase. This agreed with Petrit et al. (2014) mentioned that nurses should have adequate knowledge before initial training period at 
hospital, which prerequisite for compliance, moreover, specialized training must be received before a health care student undertakes any patient procedure involving contamination or infection.

The present study showed the percentage distribution of the military nursing staff total performance score regarding infection control measures related infectious blood parasites acquired by needle-stick injury during the program, at pre- program was $(46.7 \%)$ while at post program, and follow up and increased $(100 \%)$. There were high significant differences ( $p$-value $<0.001)$, indicating significant improvement of their performance to infection control measures related blood parasites acquired by needle-stick injury. Miguela et al. (2007) found that course content and teacher performance met the trainees' needs and all trainees acquired the necessary knowledge and skills.

The present study revealed no correlation between knowledge and performance in preprogram $(\mathrm{p}<0.001)$, but positive correlation between nurses' knowledge and performance in the post and follow up. Ibrahim et al. (2011) attributed lack of compliance to infection control standards to knowledge lack about standard infection control; poor design of the hospital unit; high work load; lack of sustainable resources and arrangements; time of contacts (daytime or night shift), and lack of training and constructive supervision, and added that efforts are needed to correct unacceptable nursing staff performance, especially where certain mismatching was noticed between what nursing staff know and what they actually done. However, significant positive correlation was found between knowledge and practice (Hamid et al, 2010; Gijare, 2012). This reflected that nursing staff performance was based on their knowledge. This agreed with Ndikom and Onibokum (2007) who found positive correlation between knowledge and practice of standard precautions

Visser et al. (2006) defined attitude as a psychological tendency expressed by evalu- ating a particular entity with some degree of favor or disfavor. So, evaluation of attitude towards certain topic can help to know the readiness of the target people to know what is new in that topic (Nabi et al, 2007). The present study showed change in the attitude of nurses throughout the training program, which achieved a highly significant improvement in nurse's attitude in all aspects.

Attitude in pre-program evaluation was noticed in re-cover the age of the needle

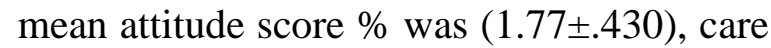
to a patient have blood parasitic diseases"

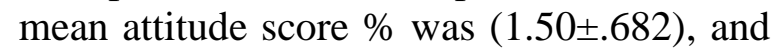
use of preventive precautions" mean attitude score \% was $(1.67 \pm .547)$ at the fever hospital. The mean attitude score $\%$ increased at post program and follow up ( $\mathrm{P}<0.001)$. At general hospital attitude in pre-program evaluation was noticed in re-cover age of the needle (1.34 \pm .479$)$, care to a patients' blood parasitic diseases (1.72 \pm .497$)$, and use of

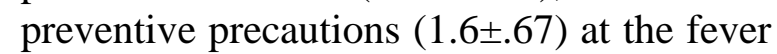
hospital and this mean attitude score $\%$ was increased at post program and follow up ( $\mathrm{P}$ $<0.001$ ). Wood (2000) found that the highest attitude score was for taking all recommended vaccines and Isolation of infected cases. Lapinski and Franklin (2001) mentioned that isolation of infected cases and valid vaccination certificate took the highest score.

In the present study, as to handling and disposal of sharps instruments nurses at the Fever Hospital $(90 \%)$ had negative attitude at pre- test. at post-program, up most (97\%) had positive attitude. However, at follow up phase, $77 \%$ had positive attitude, but, those at the General Hospital (92\%) had negative attitude at pre- test and up $98 \%$ had positive attitude at post program. However, at follow up phase, $88 \%$ had positive attitude. Also, there was high significant difference ( $p$ $<0.001$ ) indicating significant attitude improvement. This agreed with Rabaud et al. (2000) who reported proper positive attitude toward safety health among nurses especially toward vaccination.

In the present study, there was no correlat- 
ion between knowledge and attitude of nurses throughout program phases, without significant differences $(\mathrm{P}>0.05)$ between pre, post and follow-up. This agreed with Fazio and Michael (2003) who found that change of attitude directly was related to individual characteristics (especially intelligence and self-esteem), and message source characteristics specially expertise. Cialdini and Goldstein (2004) also noticed that the highly educated people could change their attitude with effective message more than less educated.

Power (2000) outlined main criteria of effective tutor; preparation, a positive optimistic outlook, passion, opens mindedness, and reliability. Undoubtedly, success of any training program depends directly upon the recipients' satisfaction of all sides of the program as tutor, materials, and place, as a key indicator (Dow et al, 2006).

In the present study, criteria of tutor showed an excellent competence with the scientific curriculum, repeating and stressing on important topics and encourage learning through being friendly and patient with trainees (100\%). About (50\%) gave very good evaluated the tutor professional and well organized and good examples. Azer (2003) mentioned that if the tutor was not efficient in the scientific content that made the trust of trainees hesitated in making the outcome of training unsatisfactory. Prideaux (2004) mentioned that if the tutor didn't prepare for the session and read the content even if he used to teach this literature this will make him not good enough. Guskey (2002) concluded that if the educator didn't give attention to the needs of the trainees this will widen the gap between both of them. Satisfaction with training and development was a major factor in decisions regarding peoples careers (Violino, 2001). Also, Thibault (2003) said that when the educator is not respondents to the questions and expectations of the trainees this will make them disjoin him and value of the literature decrease markedly.

The present study, the training materials/ teaching helped the participants as distribution of notes containing the scientific material was excellent. Teaching materials helped in information destination and maintenance to the audience, it was better to give handouts or notes that help the trainees to remember the information. About (80\%) were considered scientific materials as an excellent teaching means, about $(34 \%)$ of nurses evaluated visual and hearing as very good Randall (2007) noted that the proper training material should be suitable to the contents, and the audience, should cover all topics must be attractive, and trainees, should get handouts and brief notes about the subject. Amuwo and Jenkins (2006) said that the training materials specifically the electronic one should be clear, easy understood clear font, easy to be used by the educator or the trainees.

In the present study, 52.2\% of the nurses considered the specified Lecture duration allowed group discussion was excellent and about $(41 \%)$ found that the time specified for replying to trainees questions was excellent. While about (31\%) found that, generally how could you find lecture Duration were good. Gills (2001) recommended that the duration shouldn't be very short not to make the trainees take it lightly or too long not to make them bored. Smith and Poland (2003) noticed that the trainees in the first half an hour to one hour has the maximum level of concentration with better understanding, the concentration starts to decline markedly with high impact on the abilities to understand and concentrate.

The place of the training either made the person comfortable and willing to go to training every day or very boring and making him wish to finish any way. So In the present study, $51.3 \%$ of nurses found that the item: training room was very good equipped and clean, and (37.5\%) found that the item; supplying the training room with computer devices was fair, while $(56.3 \%)$ found that generally the training room was very good. Giachello et al. (2001) recom- 
mended that the place for training should be well ventilated, well lightened, comfortable furniture, and equipped with materials cope with the content of training. The training place should also be near or very available to the trainees (Jamal, 2004). Furnham and Christoforou (2007) noticed that the interior design of the place of training was very important to reach the message for example the U-shaped tables are very good in discussion and problem solving in addition it makes interaction between the groups more easy.

In the present study, $85 \%$ of the nurses agreed that all the trainees were informed with the intended learning outcomes and they would be evaluate after their fulfillment,(85\%) was found strongly agree that the lectures were useful \& related to the program title. All the participants agreed that the tutor was broad minded and have a good scientific background. Chen and Silverthorne (2008) reported that it was very important to meet the expectations of your trainees in order to reach the goals of the program. In addition if the program and expectations of the audience didn't meet this means great gap between the objectives and outcome. Borna and White (2003) said that if the program succeeded to reach the expectations this an indicator of performance. In the present study, $71.3 \%$ said that all topics were important. Kracher and Marble (2008) noticed that if the program tutor, contents, material were good this made all topics important to the audience.

\section{References}

Abd el-Razik, S, Abd el-Rahman, S, 2011: Needle-stick injury and its relation to infection control training program among nursing staffmember in Minia University Hospital. ENJ (Egypt. Nursing J.), 1:1146-47.

Abdenour, D, Larouze, B, Dalichaouche, M, Royal College of Nursing, 2013: Sharps safety, www.rcn.org.uk/data/assels/pdf_file/0008/41849 0/004135.pdf.

Adams, D, Down, S, Hicks, D, 2013: FIT4 Safety: Recommendations in the diabetes care setting. Br. J. Nurs. 22, 17:997-1000.

Ahmed, SM, Hassan, SA, Abd-Allah, ES,
2008: Compliance with universal precautions among nurses and laboratory technicians in Mansoura International Specialized Hospital.

Egypt. J. Hosp. Med. 30:151-64.

Alamgir, M, Bidlingmaier, W, Glawe, U, Martens, J, Sharif, L. et al, 2007: Safe and Sustainable Management of Municipal Solid Waste in Khulna City of Bangladesh. Presented to 11thInt. Waste Manag. \& Landfill Symp. Cagliari, Italy.

Alwutaib, AH, Abdulghafour, YA, Alfadhli, AK, Makboul, G, et al, 2012: Knowledge and attitude of the physicians and nurses regarding blood borne infections in primary health care, Kuwait. Greener J. Med. Sci. 2, 4:107-14

Amuwo, SA, Jenkins, E, 2006: True partnership evolves over time. In: Sullivan M, Kelly JG, editors Collaborative.

Anderson, DJ, Kirkland, KB, Mcdonald, JR, 2006: Result of a survey of work duties of 56 infection control professionals (ICPs): Are new guidelines needed for the staffing of infection control (IC) programming 207 Abstract 146. In: 16th Ann. Soc. Healthcare Epidemiol.America. Chicago.

Askarian, M, Shaghaghian, S, Gillen, M, Assadian, O, 2007: Body fluid exposure in nurses of Fars Province, Southern Iran. Arch. Iranian Med. 11, 5:515-21

Ausburn, LJ, 2004: Course design elements most valued by adult learners in blended online education environment: An American perspective. Educ. Media Int. 41, 4:327-37

Azer, SA, 2003: Assessment in a problembased learning course: twelve tips for constructing multiple choice questions that test students' cognitive skills. Biochem. Mol. Biol. 31:428-34

Borna, S, and White, G, 2003: Sex and Gender: Two confused and confusing concepts in the "Women in Corporate Management" Literature. J. Business Ethics 47:89-99.

Bouallegue, O, Naija, W, Said, H, Nouria, A, Jaidane, N, et al, 2013: Incidence of ICU acquired nosocomial infections in University Hospital of Sahloul (Sousse-Tunisia). Antimicrob. Resist. Infect. Cont.2, 1:S233-9.

Canadian Center for Occupational Health \& Safety (CCOHS), (2005): Needle sticks Injuries. Available At: au/policies/pd/200/PD2007 036.html.

Carmela, CN, Adele, M, Giuseppe, LAT, Maria, DEG, 2012: Biological risk and occupational health. Indust. Hlth. 50:326-37. 
Chen, JC, Silverthorne, C, 2008: The impact of locus of control on job stress, job performance and job satisfaction in Taiwan. Leadership Organ. Develop. J. 29, 572-582

Cialdini, RB, Goldstein, NJ, 2004: Social influence: Compliance and conformity. Ann. Rev. Psychol. 55:591-621

Considine, J, Botti, M, Thomas, S, 2007: Do knowledge and experience have specific roles in triage decision-making. Acad. Emerg. Med. 14: 7226-9.

Cummingham, JL, 1998: Critical care orientation: A comparison of two teaching methods. J. Crit. Care 17, 5:469-75'

Currie, PF, Radwin, LE, Ananian, L, Cabral, HJ, Keeley, A, 2011: Effects of a patient/ family-centered practice change on the quality and cost of intensive care: research protocol. J. Adv. Nurs. 67:215-24

Curtis, LT, 2008: Prevention of hospitalacquired infections: review of non-pharmacological interventions. J. Hosp, Infect. 69, 3:204-19. Dow, K, Alexander S, Offer, T, Jeff, W, 2006: Antecedents and consequences of user satisfaction with e-mail systems. Int. J. Collab. 2, 2:4664

Dubey, JP, Passos, IM, Rajendran, C, Ferreira, LR, Gennari, SM, et al, 2011: Isolation of viable Toxoplasma gondii from feral Guinea fowl (Numida meleagris) and domestic rabbits (Oryctolagus cuniculus) from Brazi. J. Parasitol; 97, 5:842-5

Dyson, L, Hedgecock, B, Tomkins, S, Cooke, G, 2009: Learning needs assessment for registered nurses in two large acute care hospitals in Urban New Zealand. Nurse Educ. Today 29, 8:821-8

Dyson, L, Hedgecock, B, Tomkins, S, Cooke, G, 2009: Learning needs assessment for registered nurses in two large acute care hospitals in Urban New Zealand. Nurse Educ. Today 29, 8:821-8.

El-Bahnasawy, MM, Ahmed, GM, Gaber, W A, Morsy, TA, 2013: The infantile visceral leishmaniasis: Could it attack Egyptian north coastal region again? J. Egypt. Soc. Parasitol. 43, 3: 601-8.

El-Bahnasawy, MM, Saleh, NM, Khalil, MF, Morsy, TA, 2011: The impact of three anopheline mosquito species in Toshka, on the introduction of chloroquine resistant $P$. falciparum to Egypt. J. Egypt. Soc. Parasitol. 41, 3:573-92.
Fazio, RH, Michael AO, 2003: Attitudes: Foundations, Functions, and Consequences. SageHandbook of Social Psychology London: Sage.

Ferreira, V, Teixeira, M, 2010: Healthcare waste management practices and risk perceptions: Finding from hospitals in the Algarve region, Portugal. Waste Manag. 30:265763

Fey, MK, Miltner, RS, 2000: A CompetencyBased Orientation Program for New Graduate Nurses. Jona Lippincott Williams \& Wilkins, Inc Forder, AA, 2007: A brief history of infection control- past and present. S. Afr. Med. J. 97, 11: 1161-4

Fornaciari, G, Giuffra, V, Marinozzi, et al, 2009: Royal pediculosis in renaissance Italy: Lice in the mummy of the King of Naples Ferdinand II of Aragon (1467-1496). Mem. Inst. Oswaldo Cruz 104, 4:671-2

Frankel, A, 2008: What leadership styles should senior nurses develop? Nurs. Tim.104: 35:23-4.

French, C, 2007: Basic concept of infection control. The cost of health care associated infection.

Furnham, A, Christoforou, I, 2007: Personality Traits, Emotional Intelligence, and Multiple Happiness. North Am. J. Psychol. 9, 439-62.

Galazzi, A, Rancati, S, Milos, R, 2014: A survey of accidents during the clinical rotation of students in a nursing degree program. G. Ital. Med. Lav. Ergon. 36, 1:25-31

Gershon, RR, Qureshi, KA, Pogorzelska, M, Rosen, J, Gebbie, K, et al, 2007: Non-hospital based registered nurses and the risk of bloodborne pathogen exposure. Ind. Hlth. 45:695-704. Giachello, AL, Rodriguez, G, Sayed, J, 2001: From data to social action: a case study of community-university partnership for economic justice. In: Sullivan, M, Kelly JG, editors. Collaborative research: community-university partnership. Washington: American Public Health Association.

Gijare, M, 2012: Effectiveness of teaching on infection control practices among health care professionals. Sinhgade J. Nurs. 2, 2:5-9.

Gills, DC, 2001: Unequal and uneven: critical aspects of community- university partnerships. In: Sullivan M, Kelly JG, editors. Collaborative Research: Community-University Partnership. Washington: American Public Health Association.

Giloby, N, et al, 2005: Emergency Severity Index, Version 4: Implementation Hand Book. 
Grant, J, 2002: Learning needs assessment: Assessing the need. BMJ 324:7330-8.

Guskey, TR, 2002: Professional development and teacher change. Teachers and Teaching: Theory Pract. 8:381-91

Hamid, MZA, Aziz, NA, Anita, AR, Norlijah, O, 2010: Knowledge of blood-borne infectious diseases and the practice. Southeast. Asian J Trop. Med. Pub. Hlth. 41, 5:1192-9

Herwaldt, BL, Juranek, DD, 1993: Laboratory-acquired malaria, leish-maniasis, trypanosomiasis, and toxoplasmosis. Am. J. Trop. Med. Hyg. 48, 3:313-23.

Hsieh, WB, Chiu, NC, Lee, CM, Huang, FY, 2006: Occupational blood and infectious body fluid exposures in a teaching hospital: a threeyear review. J. Microbiol. Immunol. Infect. 39, 4:321-7

Hugonnet, S, Chevrolet, J, Pittet, D, 2007: The effect of workload on infection risk in critically ill patients. Crit. Care Med. 35, 1:76- 81

Ibrahim, YS, Said, AM, Hamdy, GK, 2011: Assessment of infection control practices in neonatal intensive care unit. Egypt. J. Comm. Med. 29, 4:27-45

Ibrahim, YS, Said, AM, Hamdy, GK, 2013: Assessment of infection control practices in neonatal intensive care unit. Egypt. J. Commu. Med. 29, 4:27-45.

Idang, NO, Mfon, E, Faith, F, Margret, IA, 2014: The practice of hand washing for the preparation of nosocomial infections among nurses in general hospital Ikot Ekpene. Akwa Iborn State, Nigeria. Arch. Appl. Sci. Res. 6, 1:97-101

Institute of Medicine, IOM, 2010: The future of nursing: Leading change, advancing health: Report recommendations. http://www.iom.edu/ media/ Files/ Report0/\%Files

International Ergonomics Association (IEA), 2011: What is ergonomics? Http:/iea.cc/01_ what/ what $\% 20 \%$ is $20 \%$ ergonomics. Html.

Itrat, A, Khan, A, Javaid, S, Kamal, M, Khan, H, et al, 2009: Knowledge, awareness and practices regarding Dengue Fever among the Adult Population of Dengue Hit Cosmopolitan. PLOS One 3, 7:2620.

Jamal, M, 2004: Burnout, stress and health of employees on non-standard work schedules: a study of Canadian workers. Stress Hlth. 20:1139.

Jeff, D, 2008: A man world-career: The basic to managing work conflict. J. Men Nursing 3, 6:40-
50

Kabbash, I, El-Sayed, N, Al-Nawawy, A, Abou Salem, M, El-Deek, B, et al, 2007: Risk perception and precautions taken by health care workers for HIV infection in hemodialysis units in Egypt. East. Mediter. Hlth. J. 13, 2:392-407.

Kaye, A, 2011: Toxoplasmosis: diagnosis, treatment, and prevention in congenitally exposed infants. J. Pediatr. Hlth. Care 25, 6:355-64.

Kovats, RS, Campbell, DH, McMichael, AJ, Woodward, A, Cox, JS, 2001: Early effects of climate change: do they include changes in vector-borne disease philos Trans. R. Soc. Lond. Biol. Sci. 356:1057-68

Kracher, B, Marble, RP, 2008: The Significance of Gender in Pedicting the Cognitive Moral Development of Business Practitioners Using the Sociomoral Relation Objective Measure. J. Business Ethics, 78,503-26.

Lapinski, MK, Franklin, JB, 2001: Modeling the ego-defensive function of attitudes. Comm. Monographs 68, 3:314-24

Lynore, D, DeSilets, ED, 2007: Needs assessment: An array of possibilities. J. Conti. Educ. Nursing 38, 3:107-14

Mackintosh, N, Humphrey, C, Sandall, J, 2014: The habitus of 'rescue' and its significance for implementation of rapid response systems in acute health care. Soc. Sci. Med. 120: 233-42.

Maltezou, HC, Maragous, A, Raftopoulos, V, et al, 2008: Strategies to increase influenza vaccine uptake among health care workers in Greece. Scand. J. Infect. Dis., 40:266-8

Miguela, AC, Gabriela, M, McCullers, J, Wilfrido, A, Rafael, C, et al, 2007: Planning and Implementation of an Infection Control Training Program for Healthcare Providers in Latin America. Infect. Cont. Hosp. Epidemiol. 28, 12: 1328-33.

Molyneux, DH, 2003: Climate change and tropical disease: Common themes in changing vector-borne disease scenarios, Trans. R. Soc. Trop. Med. Hyg. 2:129-32

Nabi, RL, Moyer-Guse, E, Byrne, S, 2007: All joking aside: A serious investigation into the persuasive effect of funny social issue messages. Comm. Monographs, 74, 29-54.

National Health Service (NHS) 2005: NHS Healthcare Cleaning Manual.

Ndikom, C, Onibokun, A, 2007: Knowledge and behaviour of nurse/midwives in the prevention of vertical transmission of HIV in Owerri, Imo State, Nigeria: a cross-sectional study. BMC 
Nursing 6: 9doi:10.1186/1472-6955-6-9

Nikki, K, Campos, JD, 2010: The legalities of nursing documentation. J. Men Nurs. 40, 1:7-9

Pages, F, Fauld, M, Orlandi, E, Parola, P, 2010: The past and present threat of vectorborne disease in deployed troops, Clin. Microbial Infect. Dis. 16:209-24

Parhizi, S, Steege, IM, Pasupathy, KS, 2013: Mining the relationships between psychosocial factors and fatigue dimensions among registered nurses. Ergonomics 43, 1:82-90

Petrit, B, Migena, G, Indrit, B, 2014: Knowledge and source of information among health care students on nosocomial infections. Int. J. Human. Soc. Sci. Educ. 1, 7:46-51

Pinheiro, P, Mathers, C, Kramer, A, 2010: The global burden of infectious disease. In: Modern Infectious Disease Epidemiology; By Kramer, A, Kretzschmar, M, Krickeberg, K, New York, NY, Springer.

Pitte, D, 2001: Improving adherence to hand hygiene practice a multidisciplinary approach. Emerg. Infect. Dis. 7, 2; 214-40

Powell, E, Jones, L, Henert, E, 2002: Enhancing Program Performance with Logic Models. Retrieved December 2003, from the University of Wisconsin-Extension web site: http://www. uwex. Eud/ ces/ lmcourse

Power, AG, 2000: Insect transmission of plant viruses: a constraint on virus variability. Curr. Op. Plant Biol. 3,336-340

Prideaux, D, 2004: Promises and delivery- a research imperative for new approaches to medical education. BMJ 329:331-2

Rabaud, C, Agnes, Z, Marie, M, Francoise, B, Didier, D, et al, 2000: Occupational exposure to blood: Search for A relation between personality and behavior. Infect. Cont. Hosp. Epidemiol. 21, 9: 564-574

Randall, DA, 2007: Climate Models and Their Evaluation. In: Climate Change, USA

Rasslan, O, 2011: Infection Prevention and Control Education in Egypt: professional Diploma in Infection Control (PDIC). Int. J. Infect. Control 7:i2 doi: 10.3396/ijic.V7i2.015.11

Royal College of Nursing, 2012: Essential practice for infection prevention and control Guidance for nursing staff, London: RCN. Publication code: 004166.

Saleh AM, Ali, HA, Ahmed, SA, Hosny, SM, Morsy, TA, 2014: Screening of Toxoplasma gondii infection among childbearing age females and assessment of nurses' role in prevention and control of toxoplasmosis. J. Egypt. Soc. Parasitol. 44, 2:329-42.

Saleh, AM, Adam, SM, Abdel-Motagaly, AM, Ibrahim, AM, Morsy, TA, 2015a: Human babesiosis: A general review with special reference to Egypt. J. Egypt. Soc. Parasitol. 45, 3:493-510. Saleh, AM, Labib, A, Abdel-Fattah, MS, AlAttar, MB, Morsy, TA, 2015b: Sandfly Phlebotomus papatasi (Phlebotominae): A general review with special reference to zoonotic cutaneous leishmaniasis in Egypt. J. Egypt. Soc. Parasitol. 45, 3:525-44

Saleh, AMA, Adam, SM, Ibrahim, AM, Morsy, TA, 2016: Malaria: A general minireview with reference to Egypt. J. Egypt. Soc. Parasitol. 46, 1:35-48.

Samuel, S, Aderibigbe, S, Salami, T, Babatunde, O, 2009: Health workers knowledge, attitude and behavior towards hepatitis B infection in Southern Nigeria. Int. J. Med. Sci.1, 1:418-24

Sausa, DA, 2006: How the Brain Learns. 3rd edition; California: Carwin Press.

Sharma, R, Rasania, S, Vrrma, A, Singh, S, 2010: Study of prevalence and response to needle stick injuries among healthcare workers in a tertiary care hospital in Delhi, India. Indian J. Comm. Med. 35, 1:74-7

Siegel, J, Rhinehart, E, Jackson, M, Chiarello, L, 2007: Guideline for Isolation Precautions: Preventing Transmission of Infectious Agent in

Singru, A, Banerjee, A, 2008: Occupational exposure to blood and body fluids among health care workers in a Teaching Hospital in Mumbai, India. Indian J. Comm. Med. 33, 1:26-30

Singru, A, Banerjee, A, 2008: Occupational exposure to blood and body fluids among health care workers in a Teaching Hospital in Mumbai, India. Indian J. Comm. Med. 33, 1:26-30

Smith, SA, Poland, GA, 2003: Immunization and the prevention of influenza and pnumococcal disease in people with diabetes. Diabetes Care 26, 1:S126-8

Sreedharan, J, Muttappllymyalil, J, Venkatramana, M, 2010: knowledge and practice of standard measures in occupational exposure to blood and body fluids among nurses in a university hospital in the United Arab Emirates. Italian J. Pub. Hlth. 7:90-4

Statutory Instrument, 2013: The Health and Safety (Sharp Instruments in Healthcare) Regulations 2013 No. 645. Printed and published in the UK by the Stationery Office Limited under authority and superintendence of Carol Tullo, 
Controller of Her Majesty's Stationery Office and Queen's Printer of Acts of Parliament.

Theresa, G, Jonathan, D, Jacob K, Somashekhar, N, Norman Z, et al, 2013: Controlling health hazards to hospital workers: A Reference Guide 2013, Baywood Publishing. New solutions, Co., Inc. doi: http:/dx.doi.org/10. 2190/ NS.23.Suppl http:/baywood.com

Thibault, GE, Neill, JM, Lowenstein, DH, 2003: The academy at Harvard medical school: nurturing teaching and stimulating innovation. Acad Med; 78:673-81

Tweed, C, Tweed, M, 2008: Intensive care nurses' knowledge of pressure ulcers: Development of an assessment tool and effect of an educational program. Am. J. Crit. Care 17:338-46.

Tweed, C, Tweed, M, 2008: Intensive care nurses' knowledge of pressure ulcers: development of an assessment tool and effect of an educational program. Am. J. Crit. Care 17:338-46.

Twum-Danso, NA, Meredith, SE, 2003: Variation in incidence of serious adverse events after onchocerciasis treatment with ivermectin in areas of Cameroon co-endemic for loiasis. Trop. Med. Int. Hlth. 8:820-4.

Vaz, K, McGrowder, D, Lindo, RA, Gordon, L, Brown, P, et al, 2010: Knowledge, awareness and compliance with universal precautions among health care workers at the university hospital of the West Indies, Jamaica 1, 4:171-81.
Vij, A, Williamson, S, Gupta, S, 2001: Knowledge and practice of nursing staff towards infection control measures in a tertiary care hospital. J. Acad. Hosp. Admin. 13,2, http://www. Indme dica.

Violino, B, 2001: Still in the money. Network Computing, 12, 16: 66-9.

Visser, Penny S., Bizer, George Y, Krosnick, Jon A, 2006: Exploring the Latent Structure of Strengh-Related Attitude Attributes. Adv. Exp. Soc. Psychol. 38: 1-67

While, A, Ullman, R, Forbes, A, 2007: Development and validation of a learning needs assessment scale: a continuing professional education tool for multiple sclerosis specialist nurses. J. Clin. Nurs. 16. 6:1099-108.

WHO, 2008: Hepatitis B. Available from URL: http:/www.who.int/mediacentre/factsheets/fs204 len

WHO, 2012: WHOs response, demands of health in humanitarian emergencies. Geneva, Switzerland: http://apps.who.int/gb/ebwha/pdf_files/ WHA65/ R20-en.pdf.

Wilczyn, SKA, Szeszenia, N, Szy-mczak, W, 2005: Occupational disease in Poland. Med, Prevent. 57:225-34.

Wood, W, 2000: Attitude change: persuasion \& social influence. Ann. Rev. Psychol. 51:539-70.

Yao, WX, Yang, B, Yao, C, Bai, PX, Qian, YR, et al, 2010: NSIs among nursing students in China. Nurs. Educ. Today30:435-7

Fig.1: Socio-demographic characteristics as regard sex and rank.

\section{Explanation of figures}

Fig. 2: Socio-demographic characteristics as regard years of experience

Fig. 3: Socio-demographic characteristics as regard Qualification

Fig. 4: Training status of Nursing Staff on an educational program about infectious diseases

Fig.5: Comparison between Nursing staff Knowledge Score as regard Topics via program $(\mathrm{N}=80)$

Fig. 6: Actual total performance of Nursing Staff regarding infection control measures related blood parasites acquired by needle-stick injury

Fig. 7: Comparison between Nursing staff attitude to handling and disposal of sharps instrument via program at Fever hospital ( $\mathrm{n}=30)$

Fig. 8: Comparison between Nursing staff attitude to handling and disposal of sharps instrument via program at General hospital $(\mathrm{n}=50)$

Fig. 9: Evaluation of Tutor ( $\mathrm{N}=80)$ Fig.

10: Evaluation of training materials/teaching aids regarding as visual / hearing

Fig. 11: Evaluation of Place of Training $(\mathrm{N}=80)$

Fig. 12: Evaluation of topics of Training programs $(n=80)$ ॥I

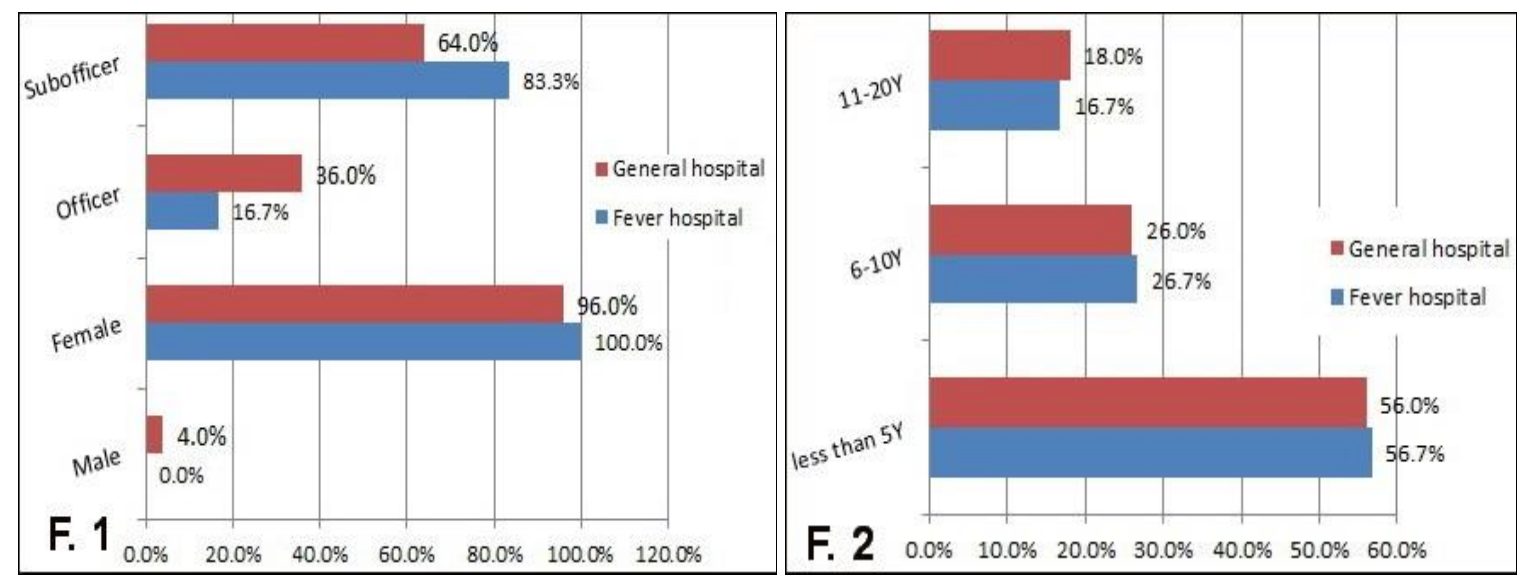



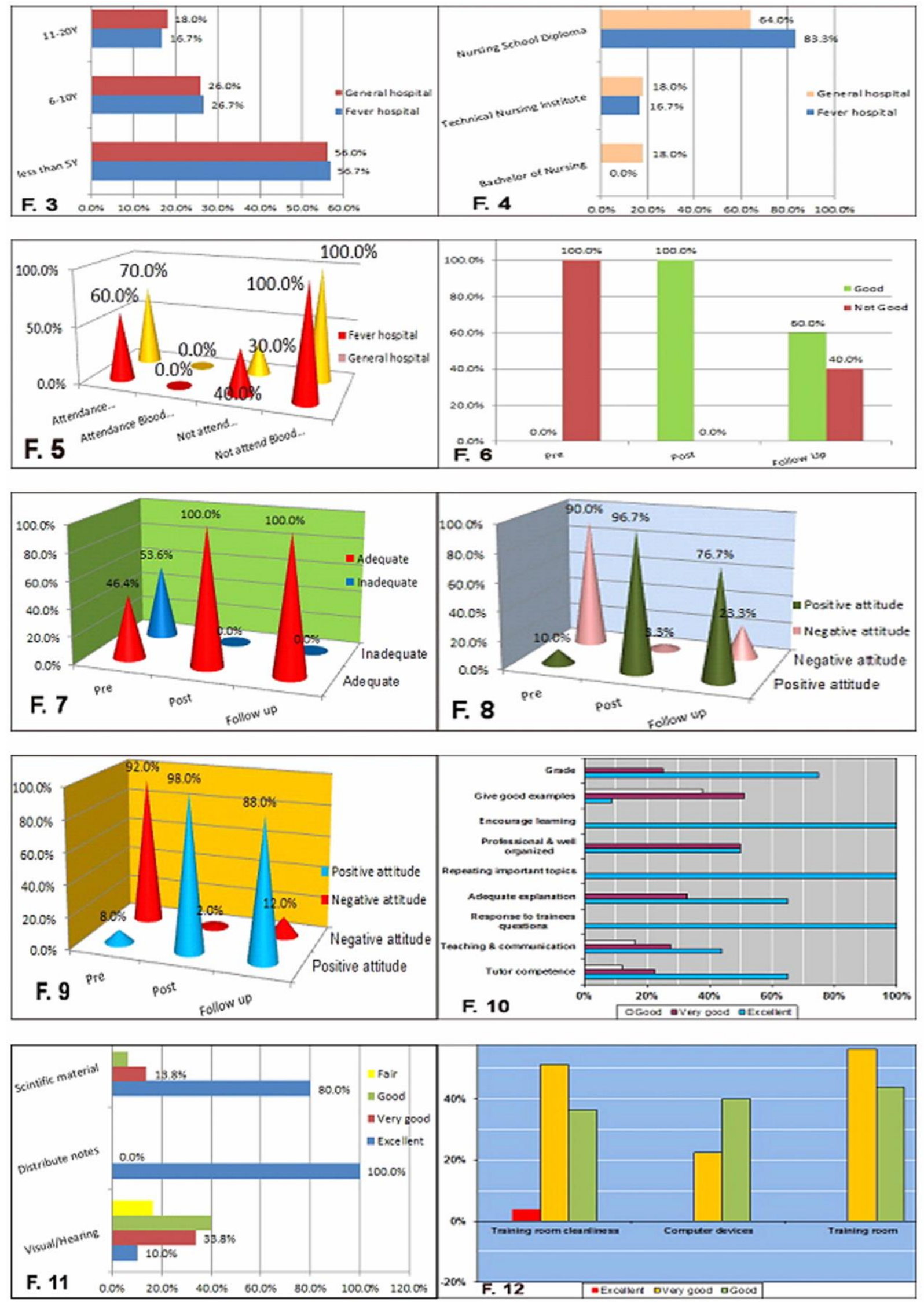